\title{
O Padrão Espacial da Atividade Inovadora Brasileira: Uma Análise Exploratória
}

\author{
- Eduardo Gonçalves*
}

\begin{abstract}
RESUMO
O objetivo deste artigo é aplicar, de forma pioneira, análise exploratória de dados espaciais sobre dados de patentes per capita para analisar a distribuição da inovação em microrregiões geográficas brasileiras. Os resultados revelam que as patentes per capita são distribuídas de forma não aleatória, indicando autocorrelação espacial positiva. A heterogeneidade espacial constatada pelo método confirma a existência de um regime de polarização Norte-Sul em termos de atividade tecnológica. Indicadores locais de associação espacial e estatísticas de Moran bivariadas são calculados com intuito de determinar a influência da vizinhança sobre a performance tecnológica das microrregiões. Os resultados mostram que a ausência de industrialização, de alto grau de escolaridade da população adulta, de pesquisadores com doutorado, de trabalhadores em áreas de formação tecnológica e de diversidade industrial e tecnológica podem funcionar como barreiras espaciais e, dessa forma, inviabilizar o processo de difusão dos transbordamentos de conhecimento.
\end{abstract}

\section{PalavRAS-CHAVE}

análise exploratória de dados espaciais, patentes per capita, autocorrelação espacial, regimes espaciais, Brasil

\begin{abstract}
The aim of this paper is to analyze the spatial distribution of innovation, measured by patents per capita, in geographical micro-regions of Brazil. This purpose is achieved by using exploratory spatial data analysis. This paper is pioneer in adopting this set of statistical tools when we look at the Brazilian innovation literature. Our findings reveal that the patents per capita are distributed non-randomly, suggesting positive spatial autocorrelation. The spatial heterogeneity confirms the existence of North-South polarization regime in terms of technological activity in Brazil. Local indicators of spatial association are also computed as well as bivariate Moran statistics as means of assessing the influence of the neighborhood on the technological performance of each microregion. We find out that the lack of some elements such as industrialization, higher-educated population, PhD researchers, workers with technological background, and technological and industrial diversity in a given microregion may be working as spatial barriers, thus precluding the diffusion process of knowledge spillovers.
\end{abstract}

\section{KEY WORDS}

exploratory spatial data analysis, patents per capita, spatial autocorrelation, spatial regimes, Brazil

\author{
JEL CLASSIFICATION \\ $018,033, R I I$
}

\footnotetext{
* Professor Adjunto da Faculdade de Economia e Administração da Universidade Federal de Juiz de Fora. E-mail: eduardo. goncalves@ufjf.edu.br. End. para contato: Universidade Federal de Juiz de Fora (UFJF) Faculdade de Economia e Administração (FEA) - CEP: 36.036-330, Campus Universitário - Juiz de Fora - MG - Brasil.

(Recebido em abril de 2005. Aceito para publicação em junho de 2006).
} 


\section{INTRODUÇÃO}

Este trabalho aplica, de forma pioneira, análise exploratória espacial aos dados de patentes brasileiras como meio de descrever o padrão espacial da inovação do País. Os dados usados são de patentes depositadas no Instituto Nacional de Propriedade Industrial (INPI), no período 1999-2001. A motivação para usar dados de patentes está associada a duas razões. De um lado, inexistem informações regionalizadas sobre P\&D no Brasil ou mesmo censos de citações de inovaçôes em revistas especializadas, como nos EUA. Mesmo a recente Pesquisa de Inovação Tecnológica (PINTEC), do Instituto Brasileiro de Geografia e Estatística (IBGE), ainda não dispõe de dados desagregados por municípios e, por isso, suas estatísticas de gastos com inovação, embora abrangentes, não podem ser diretamente submetidas a este tipo de técnica. De outro lado, as patentes oferecem rica possibilidade de investigação por áreas tecnológicas, segundo padrões internacionais de classificação, como os da Organização Mundial de Propriedade Intelectual (OMPI).

A literatura brasileira sobre inovação e desenvolvimento regional não conta com trabalhos que aplicam essa técnica. Por isso, importantes características dos dados espaciais, como a dependência e a heterogeneidade, ainda não foram adequadamente tratadas. A primeira ocorre em todas as direções, mas está inversamente relacionada à distância geográfica. A segunda diz respeito às próprias características das unidades espaciais, que naturalmente diferem entre si.

No caso brasileiro, algumas contribuições já sinalizaram a existência de concentração espacial das atividades inovadoras no Centro-Sul do País, propiciando a formulação de hipóteses a serem investigadas em trabalhos posteriores que utilizassem ferramentas analíticas mais apropriadas para lidar com dados espaciais. Por exemplo, além da concentração da atividade tecnológica nas regióes Sudeste e Sul do Brasil, Albuquerque et al. (2002) também concluíram que variáveis urbanas e espaciais explicavam, em grande parte, a localização das atividades científicas e tecnológicas.

Por meio da análise exploratória de dados espaciais, nossa proposta é confirmar a hipótese de existência, no Brasil, de um regime de polarização do tipo Norte-Sul. Além disso, espera-se que a atividade tecnológica do regime Sul ocorra no interior de um polígono ainda mais restrito e descontínuo, em relação àquele, identificado por Diniz e Crocco (1996), que deteve a tendência de reaglomeração produtiva brasileira. Segundo estes autores, as "aglomerações industriais relevantes" brasileiras estavam contidas dentro de uma área denominada "polígono industrial dinâmico", cujos vértices eram Belo Horizonte, Uberlândia, Londrina, Porto Alegre, Florianópolis, São José dos Campos, retornando a Belo Horizonte. 
Trabalho mais recente tentou delimitar as principais microrregiões em termos de potencial para abrigar e desenvolver atividades industriais e serviços modernos, compatíveis com o conceito de "Economia do Conhecimento". (Diniz e Gonçalves, 2001). Os autores verificaram que a possibilidade de o Brasil avançar em determinados segmentos da "indústria do conhecimento" dependia diretamente da qualidade do sistema acadêmico-universitário e de pesquisa pública e privada. Isto poderia consolidar e ampliar os desníveis regionais brasileiros, favorecendo as localidades melhor dotadas destes indicadores e articuladas à base produtiva regional.

Em conformidade com o tipo de perspectiva acima, as razões que apontamos para a maior concentração da atividade tecnológica no Centro-Sul do Brasil estão relacionadas aos requisitos locacionais para a mudança técnica. Nem todos os centros tecnológicos dinâmicos brasileiros são totalmente articulados e funcionalmente integrados a centros menores. Estes muitas vezes carecem de requisitos locacionais, como base industrial diversificada, escala urbana, $\mathrm{P} \& \mathrm{D}$ universitário e empresarial e recursos humanos qualificados. Nossa hipótese, portanto, é que a qualidade da vizinhança é fator essencial para o processo de transbordamento tecnológico. Por isso, o processo de difusão espacial da mudança técnica pode ser obstaculizado pela ausência desses condicionantes.

Além desta introdução, este artigo está estruturado em mais quatro seções. Na seguinte, o uso das patentes como indicadores de atividade tecnológica regional é avaliado, mostrando-se o grande número de trabalhos que usam patentes para relacionar inovação e desenvolvimento regional.

A segunda seção apresenta a base de dados, as justificativas para o recorte territorial usado e os aspectos metodológicos vinculados à análise exploratória de dados espaciais. Na terceira seção, a distribuição de patentes é caracterizada por sua significativa e positiva autocorrelação espacial global. Estatísticas espaciais locais são computadas e revelam dois tipos principais de agrupamentos, que confirmam a hipótese de heterogeneidade espacial ou o regime espacial Norte-Sul no Brasil. Localizações atípicas são também identificadas. Esta seção termina com uma análise de robustez dos resultados, por meio das matrizes de transição de probabilidades.

$\mathrm{Na}$ quarta seção, que antecede as conclusões, a vizinhança das microrregiões patenteadoras é caracterizada em função de alguns indicadores, como grau de diversificação industrial e tecnológica, grau de industrialização, escolaridade da população adulta, concentração econômica e capacidade de pesquisa universitária e empresarial. Mostrase que as microrregiões de maior atividade tecnológica estão inseridas em espaços marcados por alta diversidade industrial e tecnológica, baixa concentração econômica, 
alta escolaridade da população adulta, elevada capacidade de pesquisa universitária e grande participação de pessoal com formação tecnológica.

\section{AS PATENTES COMO INDICADORES DE ATIVIDADE TECNOLÓGICA RE- GIONAL}

Estudos que usam patentes como medida da atividade tecnológica são numerosos na literatura econômica. Griliches (1990) é uma referência clássica, pois aponta as possibilidades de uso e as limitações das patentes como indicadores econômicos. $\mathrm{O}$ autor afirma que as patentes são bons indicadores das diferenças entre atividade inventiva de firmas diferentes. A relação entre atividades de $P \& D$ e patente é forte, e na ausência de informação detalhada daquele indicador, é possível substituí-lo por este. $\mathrm{O}$ autor também é conhecido pela proposição da "função de produção de conhecimento", que relaciona medidas de insumo das atividades de $\mathrm{P} \& \mathrm{D}$, como gastos em $\mathrm{P} \& \mathrm{D}$, a medidas de produto da atividade inventiva, como patentes.

As vantagens dos dados de patentes para estudos regionais são acrescidas da possibilidade de identificar a localização do principal inventor. Na ausência de informações regionalmente desagregadas sobre $\mathrm{P} \& \mathrm{D}$, elas são uma alternativa atraente, visto que superam as suas deficiências, como a propensão a patentear variável setorialmente, a incerteza sobre seu futuro valor econômico e o fato de existirem inovações que não são protegidas por patentes. (Scherer, 1983).

Acs e Audretsch (1989) testaram empiricamente a relação das patentes com outros indicadores de performance tecnológica, como gastos em P\&D, e concluíram que elas são adequadas, embora não robustas, para a representação da atividade inovadora.

Dessa forma, a literatura de economia regional tem feito uso crescente das patentes para testar a ocorrência de transbordamentos de conhecimento e, por conseguinte, verificar a importância da proximidade geográfica para inovar. Isto é feito exatamente pela utilização da função de produção de conhecimento de Griliches, modificada por Jaffe (1989), que introduziu as dimensões espaciais.

Outra linha investigativa usa as citações de patentes para evidenciar a existência de transbordamentos de conhecimento porque elas possuem a localização de seus respectivos inventores, tornando possível o rastreamento do conhecimento. Jaffe et al. (1993) compararam a localização geográfica das citações com a patente originária que elas citam, mostrando que a localização regional dos transbordamentos importa, porque as citações ocorreram, em maior proporção, nos mesmos locais das patentes que as originaram. 
Carlino et al. (2001) adotaram patentes como medida de inovação e regrediram o patenteamento per capita de áreas metropolitanas norte-americanas contra medidas de densidade de emprego, nível de emprego, gastos universitários com P\&D, participação de grandes empresas, participação industrial no emprego total, escolaridade da população adulta, grau de concentração industrial, nível de competição local e taxa de crescimento das áreas metropolitanas. O principal resultado mostrou que há relação positiva e significativa entre densidade de emprego e patenteamento per capita, o que foi interpretado como evidência de que a proximidade espacial era importante para promover transbordamentos e, dessa forma, inovação.

Sun (2000) descreveu o padrão concentrado da atividade tecnológica na China e usou modelos de regressão tradicionais para relacionar patentes, de um lado, e variáveis relacionadas à infra-estrutura técnica e à demanda, de outro. Antes, porém, submeteu os indicadores à análise fatorial, encontrando quatro fatores classificados como nível geral de desenvolvimento regional, $\mathrm{P} \& \mathrm{D}$, abertura ao comércio exterior e aglomeração urbana. A regressão, que usou os escores fatoriais, constatou que o desenvolvimento regional está mais intensa e positivamente relacionado às patentes.

Além do seu uso em funções de produção de conhecimento, as patentes têm servido para análises que introduzem novos métodos para lidar com problemas de dependência e heterogeneidade espaciais, na linha das sugestões de Anselin (1988; 1996) e Anselin e Bera (1998).

Fischer e Varga (2003) estão entre os autores que combinaram esse redirecionamento metodológico com a função de produção de conhecimento, com o objetivo de encontrar evidências de transbordamentos de conhecimento, mediados geograficamente, da pesquisa universitária para indústrias de alta tecnologia austríacas. Os autores demonstraram que os transbordamentos apresentavam um padrão de decréscimo à medida que aumentava a distância geográfica.

Breschi (1998) submeteu os dados de patentes, considerados como bons indicadores de competência tecnológica de firmas e regióes, à análise exploratória de dados espaciais para verificar se a inovação era concentrada e para descrever os diferentes sistemas espaciais de províncias inovadoras da Itália. Foi possível concluir que a atividade inovadora italiana era mais concentrada espacialmente que a atividade produtiva e a população.

Moreno-Serrano et al. (2004) encontraram autocorrelação espacial positiva para 175 regiôes européias. Os autores também tentaram modelar, por meio de econometria espacial, os determinantes do processo local da inovação, com auxílio da função de produção de conhecimento de Griliches, modificada com a inclusão das seguintes va- 
riáveis explicativas: densidade populacional, emprego industrial e dummies para captar influência de fatores institucionais nacionais. De modo geral, gastos em P\&D das regiões e de seus vizinhos, economias de aglomeração e fatores institucionais, além da atividade tecnológica dos vizinhos, importavam na explicação do patenteamento per capita. Os autores também demonstraram que o processo de difusão do conhecimento diminuía sua intensidade à medida que aumentava a distância geográfica.

A seção seguinte apresenta os dados de patentes usados neste artigo, assim como as justificativas para o recorte regional adotado.

\section{BASE DE DADOS E PROCEDIMENTOS METODOLÓGICOS}

Este trabalho faz uso da base de dados do INPI, que totalizava 16.884 patentes depositadas no período 1999-2001, referentes a 886 municípios. Essa base de dados será investigada a partir do recorte territorial das microrregiões geográficas como unidade de análise pelos seguintes motivos:

1) tentar minimizar o problema de falta de correspondência entre a unidade políticoadministrativa adotada e a escala territorial na qual o processo de inovação ocorre. Metodologicamente, não parece adequado separar Belo Horizonte de Betim e Contagem numa análise sobre a dinâmica industrial e tecnológica da capital mineira. A microrregião de Belo Horizonte tem a vantagem de agregar os dois municípios citados. De forma semelhante, não pairam dúvidas sobre a adequação de se tratar conjuntamente a dinâmica econômica e tecnológica de municípios como Campinas, Jaguariúna e Sumaré ou mesmo de São Paulo com os municípios da região do $\mathrm{ABC}$;

2) a literatura brasileira que usa microrregião como unidade de análise é também um precedente importante para nossa escolha. Diniz e Gonçalves (2001) selecionaram as principais localidades (microrregiões) brasileiras para avaliar o impacto da desigualdade regional de indicadores vinculados à indústria do conhecimento sobre a concentração industrial brasileira e sua tendência reforçadora do padrão de desenvolvimento macrorregional brasileiro. Silva e Simões (2004) usaram microrregiões para entender a relação entre a interação entre atividades científicas e produtivas e a criação de oportunidades tecnológicas.

Por outro lado, processos de difusão que ocorram apenas sob distâncias reduzidas, de um município para outro na mesma microrregião, não podem ser detectados na nossa análise. Mesmo assim, as microrregiões geográficas, pelas razões discutidas 
acima, são um bom ponto de partida para a questão regional da atividade tecnológica no Brasil.

Consideramos que métodos convencionais, como regressões múltiplas e inspeção visual de mapas, não são as formas mais adequadas de lidar com dados georreferenciados, pois não são confiáveis para detectar agrupamentos e padrões espaciais significativos. Como afirmam Messner et al. (1999, p. 427), "a percepção humana não é suficientemente rigorosa para determinar agrupamentos significativos e, de fato, tende a ser enviesada para achar padrões, mesmo em dados espaciais aleatórios." Dessa forma, utilizaremos a análise exploratória de dados espaciais como primeiro passo para revelar padrões espaciais, que devem anteceder quaisquer modelos econométricos espaciais.

\subsection{Análise Exploratória de Dados Espaciais}

A análise exploratória de dados espaciais é útil para descrever distribuições espaciais, revelando padrões de associações espaciais (clusters espaciais), regimes espaciais ou outras formas de instabilidade espacial (não-estacionariedade) e observações atípicas (outliers). Como dito anteriormente, a principal vantagem desta técnica é tratar os efeitos espaciais, termo usado para fazer referência à dependência e à heterogeneidade espaciais. A primeira ocorre em todas as direções, mas está inversamente relacionada à distância geográfica. A segunda diz respeito às próprias características das unidades espaciais, que naturalmente diferem entre si. (Anselin, 1996; Varga, 1998; Le Gallo e Ertur, 2003).

Como medida de dependência usaremos o $I$ de Moran, ${ }^{1}$ que é calculado como se segue: $I=\left(n / \sum_{i j} w_{i j}\right) \sum_{i j} w_{i j}\left(x_{i}-\mu\right) / \sum_{i}\left(x_{i}-\mu\right)^{2}$

em que $n$ é o número de observações, $x$ é a variável analisada, $\mu$ é a média de $x, w_{i j}$ são os elementos da matriz de pesos espaciais e os subscritos $i$ e $j$ referem-se aos pares de localizações. Em essência, o indicador acima equivale ao grau de associação linear entre o vetor de valores observados $(z)$ e a média ponderada de valores vizinhos $(\mathrm{Wz})$. Valores maiores (menores) que o esperado indicam autocorrelação espacial positiva (negativa). ${ }^{2}$

Usaremos a abordagem da permutação para fazer inferência sobre $I$. Neste caso, gerase empiricamente uma distribuição de referência, que computa média e desvio padrão. Segundo Anselin (1992), este procedimento reordena aleatoriamente os valores ob-

1 Outras medidas globais de associação espacial são: a estatística de Geary, as estatísticas de associação conjunta e a estatística de Getis e Ord. (Varga, 1998).

2 O valor esperado do $I$ de Moran é -[1/(n-1)], que seria obtido caso houvesse distribuição aleatória dos dados. 
servados sobre todas as localizações, refazendo-se a estatística $I$ para cada nova amostra. ${ }^{3}$ Desta forma, o valor do $I$ de Moran é comparado com a distribuição artificial da estatística, sob a hipótese nula de ausência de associação espacial, o que significa ocorrência das observaçôes em qualquer lugar com igual probabilidade.

A matriz de pesos espaciais usada no trabalho foi condicionada pelo procedimento de cálculo do I de Moran para apenas valores de patentes maiores que zero, como exposto acima. Neste caso, a melhor forma de estabelecer a estrutura de vizinhança foi via conceito dos $k$ vizinhos mais próximos, calculados a partir da distância do grande círculo entre os centróides das microrregiões, com $k$ variando de 10 a $30 .{ }^{4}$ Para verificar se os resultados são estáveis, mesmo variando o número de vizinhos, foi construída uma matriz de transição de probabilidades. O I de Moran será interpretado como um coeficiente de ajuste de uma regressão de $W z$ sobre $z .^{5}$

Embora seja capaz de apontar a tendência geral de agrupamento dos dados, o $I$ de Moran é uma medida global e por isso não revela padrões locais de associação espacial, ou seja, a estrutura regional de autocorrelação espacial. Existem duas ferramentas para verificar esta estrutura: o diagrama de dispersão de Moran e os indicadores locais de associação espacial, conhecidos como "LISA". Estes são usados para testar a hipótese nula de distribuição aleatória pelo fato de comparar os valores de cada localização específica com os valores de seus vizinhos.

O diagrama de dispersão de Moran apresenta a tendência geral de associação por meio da reta que mostra como os dados se ajustam entre os valores defasados espacialmente $(W z)$ e os valores observados em cada unidade espacial (z), além das tendências locais, representadas por cada ponto no interior do diagrama. Como os valores de $z \mathrm{e}$ Wz são padronizados, é possível identificar valores discrepantes (outliers) e pontos de alavancagem (leverage points). Segundo Varga (1998), localizaçôes que são extremas à tendência central, e que por isso não seguem o mesmo processo de dependência espacial que a maioria das observações, são outliers e aquelas que têm grande influência sobre a tendência central são pontos de alavancagem. Se a reta de regressão tiver inclinação positiva, os pontos que estiverem a mais de dois desvios padrão do centro nos quadrantes superior esquerdo e inferior direito são considerados outliers. Se isto ocorrer no quadrante superior direito e no inferior esquerdo, temos pontos de alavancagem. Os valores discrepantes serão identificados pela distância de Cook e pela regra de dois desvios padrão. ${ }^{6}$

3 As outras duas abordagens supõem distribuição normal e a aleatoriedade.

4 A título de comparação, estimou-se a estatística $I$ de Moran para todo o conjunto de 558 microrregióes por meio das matrizes de contigüidade binária, segundo convenção Queen e Rook. Ambas apontaram associação espacial positiva.

5 A padronização pela linha no caso de matrizes baseadas nos $k$ vizinhos mais próximos não é necessária porque ambas, padronizadas ou não, geram os mesmos resultados.

6 Mais detalhes podem ser vistos em Anselin (1995a). 
Outra vantagem do diagrama de dispersão é poder classificar as associações espaciais locais entre as microrregiôes e seus vizinhos de acordo com os seguintes resultados: 1) Padrão Alto-Alto (AA): revela microrregióes com alto valor da variável sob análise, cercada de vizinhos que também possuem valores semelhantes (quadrante superior direito); 2) Padrão Baixo-Baixo (BB): revela microrregiões com baixo valor, circundadas por outras de valores também baixos (quadrante inferior esquerdo); 3 ) Padrão AltoBaixo (AB): aponta microrregiões de alto valor que possuem vizinhos com baixo valor (quadrante inferior direito); 4) Padrão Baixo-Alto (BA): aponta microrregiões de baixo valor que são vizinhas de outras com alto valor (quadrante superior esquerdo).

Os padrões $\mathrm{AA}$ e $\mathrm{BB}$ revelam associação espacial positiva, enquanto que $\mathrm{BA}$ e $\mathrm{AB}$, associação espacial negativa.

Ainda que seja tão útil quanto mostrado, o diagrama de Moran precisa ser complementado com os indicadores LISA, porque não fornece indicações da significância do agrupamento espacial. Segundo Anselin (1995b), indicadores LISA devem propiciar uma medida do grau em que o agrupamento espacial de valores locais similares é significativo e devem ter soma proporcional ao indicador global. Eles podem ser definidos como se segue: $I_{i}=\left[\left(x_{i}-\mu\right) /\left(\Sigma_{i}\left(x_{i}-\mu\right)^{2} / n\right)\right] \Sigma_{j} w_{i j}\left(x_{j}-\mu\right)$

em que $I_{i}$ é o Moran Local para a observação $i$ e $n, x, \mu$, wij seguem notação anterior.

O indicador Moran Local avalia a significância dos agrupamentos espaciais locais, conhecidos como hot spots, ao redor de uma localização individual e indica focos (pockets) de não-estacionariedade espacial (localizações atípicas). Também sugere a presença de observações discrepantes ou regimes espaciais, semelhante ao uso do diagrama de dispersão de Moran.

Da mesma forma, ao lado dos casos em que essa estatística não é significativa, os mesmos quatro padrões do diagrama de dispersão de Moran podem ser visualizados num mapa, conhecido como Mapa de Significância de Moran. Os valores de probabilidade fornecidos ( $p$-values) devem ser vistos como níveis de pseudo-significância, tendo em vista que as inferências são feitas a partir da abordagem das permutações.

No nosso caso, os cálculos das estatísticas I de Moran e do Moran Local foram realizados apenas para as microrregióes patenteadoras. Este procedimento foi adotado por Varga (1998) para evitar que um grande número de zeros provocasse redução do valor médio e um aumento potencial dos agrupamentos de valores altos, visto que tanto o $I$ de Moran quanto o Moran Local possuem, em suas fórmulas, as somas das diferenças entre cada valor observado e a média dos valores observados. No nosso caso, esse procedimento se justifica porque, do total de 558 microrregióes, apenas $321(57,5 \%)$ têm pelo menos uma patente. 


\section{ANÁLISE DOS RESULTADOS}

\subsection{Distribuição da Atividade Tecnológica Brasileira por Microrregiões Principais}

As Tabelas 1 e 2 apresentam as dez principais microrregiões patenteadoras do Brasil em termos absolutos e relativos, respectivamente.

TABELA I - NÚMERO DE PATENTES POR MICRORREGIÓES (1999-2001)

\begin{tabular}{llc}
\hline Microrregião & UF & Patentes \\
\hline São Paulo & SP & 5130 \\
Rio de Janeiro & RJ & 1259 \\
Belo Horizonte & MG & 905 \\
Curitiba & PR & 793 \\
Porto Alegre & RS & 740 \\
Campinas & SP & 563 \\
Caxias do Sul & RS & 406 \\
Brasília & DF & 329 \\
Joinville & SC & 299 \\
Osasco & SP & 284 \\
\hline
\end{tabular}

Fonte: elaboração própria com base nos dados do INPI.

Na Tabela 1 , as cinco primeiras microrregiões coincidem com os centros mais industrializados do País, respondendo por mais da metade das 16.884 patentes registradas pelo INPI para o período de 1999-2001. Entretanto, a importância de cada microrregião não pode ser adequadamente aferida pelo número absoluto de patentes. É preciso normalizá-lo pela população da região. A Tabela 2 contém o ordenamento das dez primeiras microrregiões, o qual é substancialmente diferente daquele mostrado pela Tabela 1. Apenas as localidades de São Paulo, Campinas, Joinville e Curitiba são comuns às duas listas.

É interessante notar que a microrregião de São Paulo perde a liderança na Tabela 2 e que Caxias do Sul possui o índice mais elevado, com mais de seis patentes para cada 10.000 habitantes. Ainda que estas tabelas sejam úteis para mostrar a concentração da inovação em poucas microrregiões do País, sua distribuição espacial precisa ser analisada sob o rigor de ferramentas mais apropriadas, vinculadas à análise exploratória de dados espaciais. 
TABELA 2 - NÚMERO DE PATENTES NORMALIZADO PELA POPULAÇÃO

\begin{tabular}{llc}
\hline Microrregião & UF & Patentes per capita* $^{*}$ \\
\hline Caxias do Sul & RS & 6,21 \\
Joinville & SC & 4,40 \\
São Paulo & SP & 4,01 \\
Blumenau & SC & 3,29 \\
Curitiba & PR & 2,98 \\
São Carlos & SP & 2,94 \\
Marília & SP & 2,87 \\
Londrina & PR & 2,80 \\
Campinas & SP & 2,55 \\
Passo Fundo & RS & 2,40 \\
\hline
\end{tabular}

* Patentes por 10.000 habitantes.

Fonte: elaboração própria com base nos dados do INPI.

\subsection{Autocorrelação Espacial Global e o Diagrama de Dispersão de Moran}

A primeira forma de conferir maior rigor metodológico a uma análise que tem por objetivo descrever a distribuição espacial da atividade inovadora no Brasil, como visto, é calcular a estatística global de Moran. O principal propósito desta estatística é confirmar ou não a hipótese de dados aleatoriamente distribuídos.

A Tabela 3 contém a estatística $I$ de Moran para cinco diferentes matrizes de pesos. Em todas é possível rejeitar a hipótese nula de distribuição aleatória da variável patente per capita sobre o território brasileiro ao nível de significância de $0,01 \%$. O valor positivo para a estatística aponta para autocorrelação espacial positiva. Isto significa que microrregióes com elevado índice de patentes per capita são vizinhas de outras microrregiões que também apresentam elevado patenteamento per capita, ou vice-versa. Nota-se também que o coeficiente de Moran decai à medida que aumenta o número de vizinhos. Isto equivale a dizer que a dependência espacial entre as microrregiões diminui à medida que aumentamos a extensão territorial da vizinhança ou que unidades mais longínquas são consideradas vizinhas daquelas, sugerindo a importância da proximidade para os transbordamentos de conhecimento. 
TABELA 3 - INDICADOR GLOBAL DE AUTOCORRELAÇÃO ESPACIAL PARA PATENTES PER CAPITA POR MICRORREGIÓES BRASILEIRAS

\begin{tabular}{lcccc}
\hline Matriz de Pesos & I de Moran & Média & Desvio Padrão & Probabilidade* $^{*}$ \\
\hline 10 vizinhos mais próximos & 0,30 & $-0,003$ & 0,023 & 0,0001 \\
15 vizinhos mais próximos & 0,27 & $-0,003$ & 0,018 & 0,0001 \\
20 vizinhos mais próximos & 0,24 & $-0,003$ & 0,016 & 0,0001 \\
25 vizinhos mais próximos & 0,21 & $-0,003$ & 0,014 & 0,0001 \\
30 vizinhos mais próximos & 0,19 & $-0,003$ & 0,013 & 0,0001 \\
\hline
\end{tabular}

*Pseudo-significância empírica baseada em 10.000 permutações.

Fonte: elaboração própria com base no programa SpaceStat ${ }^{\mathrm{TM}}$.

O próximo passo da análise é verificar se há microrregiões que se afastam do padrão global de associação positiva, mostrado pelo $I$ de Moran, assim como possíveis valores discrepantes globais. O diagrama de dispersão de Moran (Figura l) apresentado é o referente aos 30 vizinhos mais próximos. Ele revela que $69 \%$ das microrregiões são caracterizadas por associação positiva, pois cerca de $24 \%$ pertencem ao quadrante superior direito (classificação AA) e 44,5\% pertencem ao quadrante inferior esquerdo (classificação BB). Os outros $31 \%$ desviam do padrão global, sendo que $6,5 \%$ pertencem ao quadrante inferior direito (classificação $\mathrm{AB}$ ) e $24,9 \%$ pertencem ao quadrante superior esquerdo (classificação BA). Com isto é possível afirmar que há dois regimes de autocorrelação espacial, o primeiro correspondendo ao regime AA e o segundo ao regime $\mathrm{BB}$.

A microrregião de Caxias do Sul é ponto de alavancagem no Sul do Brasil. O excelente potencial inovador desta microrregião é claramente demonstrado pelo diagrama de dispersão de Moran. Com exceção de Passo Fundo e Porto Alegre, pode-se notar que sua vizinhança não é muito rica em termos de capacidade inovadora. Joinville, São Paulo, Curitiba e São Carlos têm padrão diferente, pois seus vizinhos possuem bom potencial inovador. Marília e Londrina são caracterizadas por uma vizinhança muito pobre em termos de potencial inovador, tendo em vista que estão sobre o eixo das abscissas.

Algumas destas microrregióes constituem valores discrepantes. Caxias do Sul, Joinville e São Paulo, também destacados pela Tabela 2, aparecem como valores discrepantes na Tabela 4. Esta tabela é importante porque segundo Anselin (1995a, p. 46) "regióes que exercem grande influência ou alavancagem sobre a inclinação da reta de regressão (ou seja, sobre o I de Moran) são de interesse, principalmente se são espacialmente agrupados ou se correspondem a regiões de fronteira." A medida usada para identificar esses pontos influentes foi a distância de Cook, sendo apresentada na Tabela $4 .^{7}$

7 Mais detalhes sobre esse critério podem ser consultados em Anselin (1995). 
FIGURA 1 - DIAGRAMA DE DISPERSÃO DE MORAN: PATENTES PER CAPITA

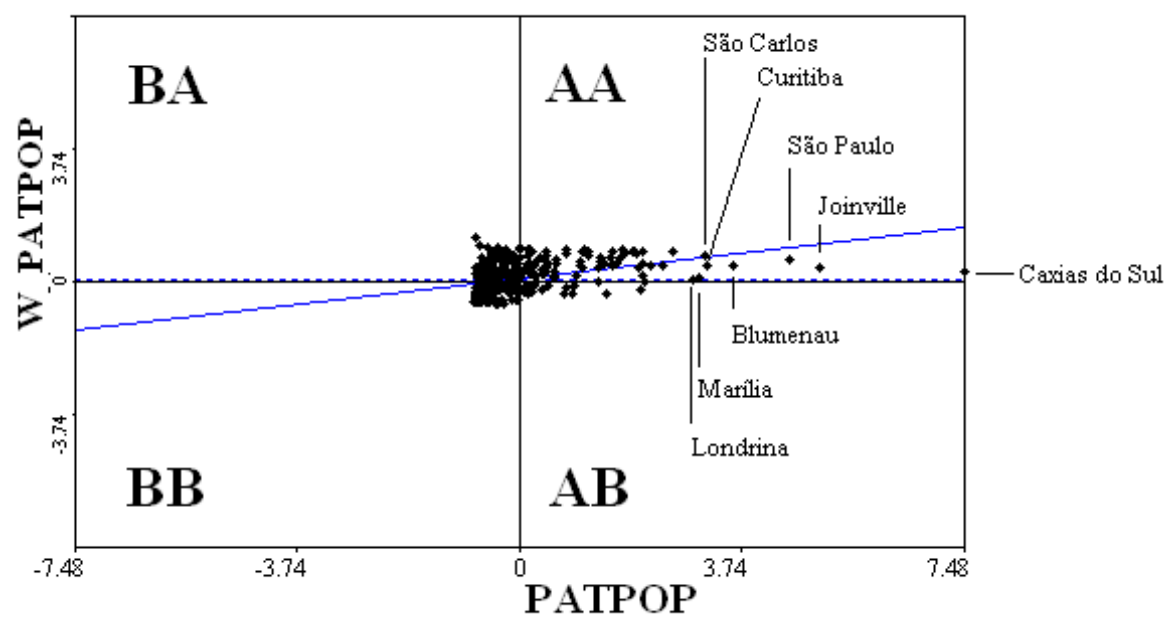

Obs.: PATPOP $=$ Patenteamento Per Capita.

W_PATPOP = Defasagem espacial do Patenteamento Per Capita.

Fonte: elaboração própria com base no programa $\operatorname{ArcGIS}^{\mathrm{TM}}$.

TABELA 4 - MICRORREGIÕES INFLUENTES SEGUNDO A DISTÂNCIA DE COOK

\begin{tabular}{llc}
\hline Microrregião & UF & Distância de Cook \\
\hline Caxias do Sul & RS & 1,1297 \\
Joinville & SC & 0,1262 \\
Londrina & PR & 0,0301 \\
Marília & SP & 0,0273 \\
São Paulo & SP & 0,0250 \\
Belo Horizonte & MG & 0,0235 \\
Registro & SP & 0,0229 \\
Campos de Lages & SC & 0,0150 \\
Blumenau & SC & 0,0145 \\
Guarapari & ES & 0,0142 \\
\hline
\end{tabular}

Nota: Distância de corte $=0,0125$.

Fonte: elaboração própria com base no programa SpaceStat ${ }^{\mathrm{TM}}$.

As dez observações extremas contidas na Tabela 4 possuem distância de Cook que é superior ao limite de corte $(0,0125)$, o qual equivale a duas vezes o número de vari- 
áveis da regressão de W_PATPOP sobre PATPOP (no nosso caso, 4), dividido pelo número de observações da amostra (321 microrregiões). Se retirássemos da amostra essas microrregióes influentes, o $I$ de Moran mostraria grau de associação positiva bem maior: igual a 0,33 .

$\mathrm{Na}$ subseção seguinte serão apresentados os indicadores locais de associação espacial que conferem maior rigor estatístico à análise.

\subsection{Autocorrelação Espacial Local}

A estatística LISA é apropriada para identificar agrupamentos espaciais significativos e instabilidade local da medida de associação global ( $I$ de Moran), revelada por valores espaciais extremos, conforme já indicado anteriormente. A hipótese nula continua sendo a de ausência de associação espacial, embora agora local. Outra vantagem desta análise é que podemos associar as estatísticas locais de Moran ao diagrama de dispersão de Moran, produzindo o chamado Mapa de Significância de Moran.

A tendência global de associação positiva, revelada pela estatística $I$ de Moran da seção anterior, é confirmada pelas estatísticas locais de Moran. Cerca de 75,6\% das estatísticas significativas, ao nível de pseudo-significância de $5 \%$, caem nos quadrantes I ou III do diagrama de dispersão, os quais representam agrupamentos AA ou BB. Contudo, há distribuição desigual entre as associações $\mathrm{AA}$ e $\mathrm{BB}$, tendo em vista que $61,8 \%$ das microrregiões pertencem à última. Assim, a maior parte das microrregiões possui baixa atividade inovadora, cercada de vizinhos cujo desempenho inovador também é reduzido. Outra conclusão é que os desvios da tendência global se reduzem a $24,4 \%$ dos casos. Dentre os dois tipos de associação espacial negativa, há predomínio $(83,7 \%)$ do tipo BA. Os outros $16,3 \%$ equivalem a oito casos $\mathrm{AB} .{ }^{8}$

Na Figura 2 é possível visualizar esses regimes espaciais da inovação no Brasil, que aponta evidências de agrupamento espacial. As macrorregiões Norte e Nordeste e vasta maioria do Centro-Oeste despontam pela sua homogeneidade em termos de baixa atividade tecnológica, confirmando a existência, no Brasil, do fenômeno de polarização Norte-Sul. Por isso, é perfeitamente válida a caracterização desta grande extensão ter-

8 Essas microrregiões, em ordem decrescente de grandeza do patenteamento per capita, são: Belo Horizonte (MG), Guarapari (ES), Canarana (MT), Cuiabá (MT), Primavera do Leste (MT), Barra de São Francisco (MG) e Ipatinga (MG). Destas, algumas apresentam um número absoluto de patentes muito pequeno (abaixo de 10), como é o caso de Canarana, Barra de Sáo Francisco e Primavera do Leste, apenas se destacando em razão de sua vizinhança, que é muito pobre em termos de atividade tecnológica. De todas, Belo Horizonte é a única que apresenta notório potencial tecnológico superior. 
ritorial brasileira como "Região Vazia e Estagnada", em relação ao seu potencial para gerar atividade produtiva intensiva em conhecimento. (Diniz e Gonçalves, 2001).

Ao contrário, as macrorregiões Sudeste e Sul apresentam maior riqueza de padrões espaciais de inovação. Os padrões AA estão, em sua maior parte, no Estado de São Paulo. Como os transbordamentos tecnológicos são fundamentais para fomentar a inovação, o estado demonstra sua força ao ser capaz de reunir número tão expressivo de microrregiões com alto indicador de patentes per capita, que também são vizinhas de outras microrregiões que apresentam valores semelhantes para esta variável.

Pode-se notar que além de ser o maior agrupamento espacial do tipo AA em termos de número de microrregióes e extensão territorial, dificilmente ocorrem descontinuidades nele, em termos da presença de microrregiões de baixa atividade tecnológica ou mesmo de microrregiões não significativas ou de patenteamento zero. Este polígono de alta atividade tecnológica estende-se de São Paulo e vizinhos mais próximos como Osasco, Santos e Guarulhos até Franca, Ituverava, Barretos e São José do Rio Preto (norte e noroeste do estado, próximo de Uberaba), passando por Campinas, Piracicaba, São Carlos, Araraquara e Ribeirão Preto, mais ao centro do Estado.

A microrregião de São Paulo e suas adjacências despontam como o principal centro econômico do País, tanto pela presença e concentração de atividades industriais, de serviços modernos, de instituições financeiras, de sedes de grandes grupos nacionais e de corporações multinacionais quanto pela excelente infra-estrutura e amenidades urbanas. A riqueza e magnitude destas economias de aglomeração explicam a alta atividade tecnológica presente na região. A extensão territorial da aglomeração de atividade tecnológica do tipo AA se explica pela presença de uma rede de cidades de porte médio capazes de absorver quaisquer transbordamentos de conhecimento tecnológico que se originem em empresas inovadoras ou em instituições públicas e privadas de pesquisa. Fazem parte desta rede, como cidades que ocupam posição de destaque na hierarquia do tipo da que foi concebida por Christaller (1966), São José dos Campos, Campinas, Sorocaba, Araraquara, Ribeirão Preto, Piracicaba, para citar algumas. A existência desta densa e complexa rede urbana foi também uma das razões apontadas para explicar o fato de ter não ter havido alteração substancial no quadro das desigualdades regionais do Brasil com a perda relativa de importância industrial da região metropolitana de São Paulo nas décadas de 1970 e 1980, conforme descrito em Diniz (1993; 1999). Em outras palavras, essa perda relativa de importância favoreceu primordialmente o interior do próprio Estado de São Paulo, porque, em parte, inexistiam economias de aglomeração em outros centros urbanos de outras regiões do País. 


\section{FIGURA 2 - MAPA DE SIGNIFICÂNCIA DE MORAN PARA PATENTEAMENTO PER CAPITA}
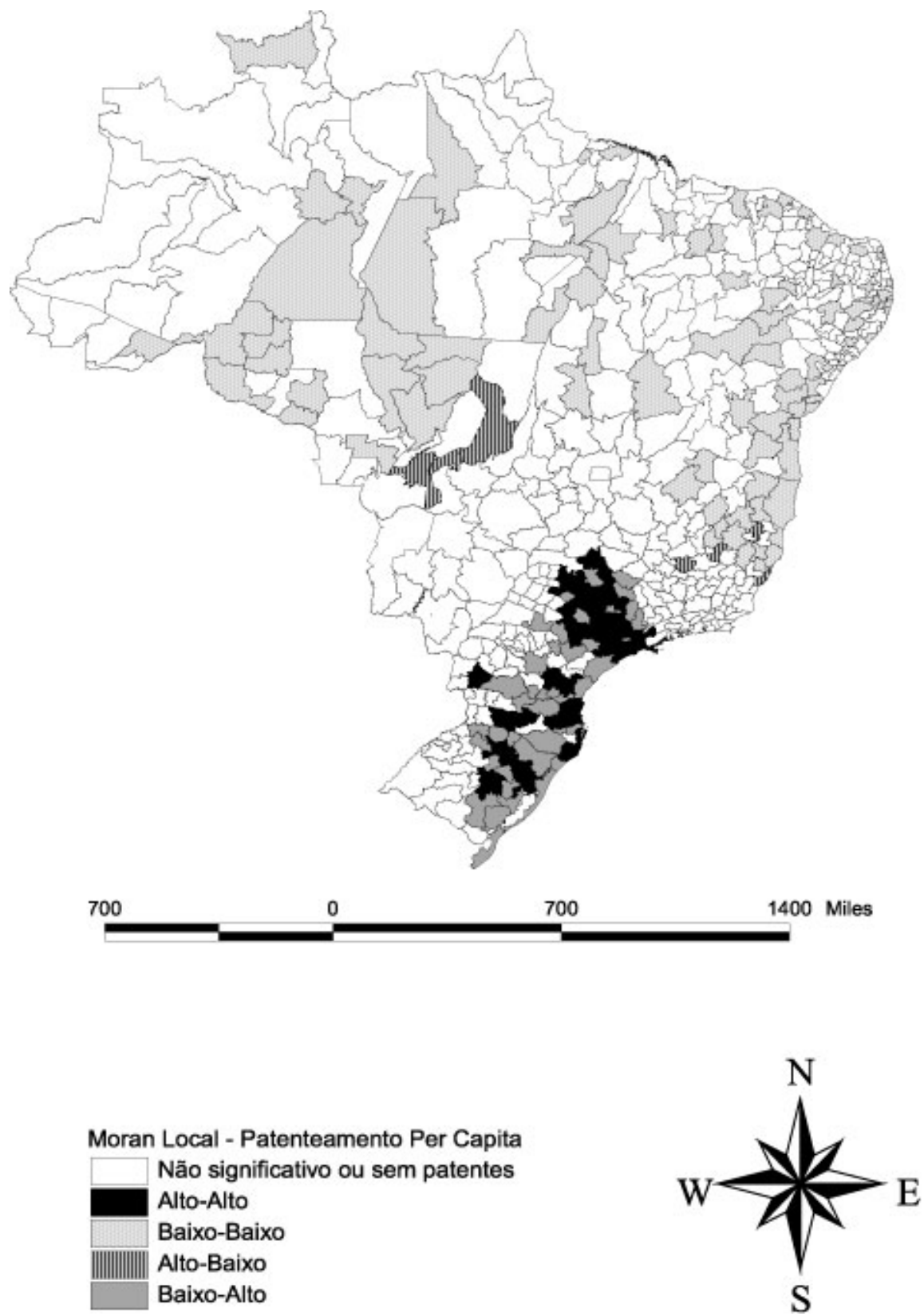

Fonte: elaboração própria com base no programa $\operatorname{ArcGIS}^{\mathrm{TM}}$.

Com base em Diniz e Razavi (1999), é possível mencionar importantes empresas de grande porte nacionais e multinacionais instaladas na região de Campinas: MercedesBenz, Bosch, Clark, Singer, Schudl, Rhodia, 3M, Merck e Sharp. Nos casos da IBM, 
Ericsson, Alcaltel, Texas Instuments, ABC, Promon, Compaq, Motorola, Lucent Technologies, Avex Eletronics, Nortel é clara a influência do poder de atração de instituições locais de ensino e pesquisa, como a Unicamp, o Centro Tecnológico de Informática, o CPqD da antiga Telebrás e o Laboratório Nacional de Luz Síncroton. São José dos Campos destaca-se por abrigar filiais de multinacionais e empresas do setor bélico e aeroespacial, como a Embraer, mas também pela presença do Centro Tecnológico da Aeronáutica (CTA) e do Instituto Tecnológico da Aeronáutica (ITA).

O Estado de São Paulo também possui microrregiões que são BA, sendo que algumas estão no interior deste polígono de alta atividade tecnológica (São João da Boa Vista, São Joaquim da Barra e Franco da Rocha). Porém, a maioria é externa ao polígono, como Registro, Itapetininga, Ourinhos, Itapeva, Assis e Novo Horizonte. Algumas microrregiões BA são mineiras, como Passos, São Sebastião do Paraíso, Poços de Caldas e Pouso Alegre. Estas são as regiões de Minas Gerais que se beneficiaram do processo de desconcentração relativa da área metropolitana de São Paulo. Mas os principais beneficiários deste processo, pelo menos em termos tecnológicos, foram as próprias microrregiões do interior do Estado paulista, citadas no parágrafo anterior, de tal forma que criaram o maior cluster AA do País.

O Estado de Minas Gerais aparece como um grande espaço vazio em termos tecnológicos. As exceções são as microrregiões que fazem vizinhança com o Estado de São Paulo, já citadas, e Belo Horizonte, que desponta como AB, juntamente com Ipatinga.

Outras aglomerações compõem o regime BB, mais típico da macrorregião "Estagnada e Vazia” do regime Norte de inovação brasileiro. Estas são Montes Claros, Janaúba, Capelinha, Governador Valadares, Aimorés, Teófilo Otoni, Peçanha, Nanuque e Almenara. Entretanto, devido à carência de infra-estrutura urbana básica, produtiva e tecno-científica destas microrregiões, dificilmente conseguirão superar, a curto e médio prazo, sua situação atual.

Algumas ausências da Figura 2 devem ser assinaladas. Dentre estas estão Juiz de Fora e Uberlândia, cujas aglomerações existentes não são estatisticamente significativas a $5 \%$. Este resultado não confirma o anterior, mostrado pelo diagrama de dispersão de Moran (Figura 1), em que a primeira aparecia no quadrante inferior direito (AB) e a segunda no quadrante superior direito (AA). Outra ausência se refere a todas as microrregiões do Estado do Rio de Janeiro. De fato, o índice de patenteamento per capita destas microrregiões não é tão elevado quanto se poderia esperar. No caso do Rio de Janeiro, Juiz de Fora e Uberlândia, estes índices são 1,18, 0,95 e 0,94, respec- 
tivamente, os quais se distanciam da capital mineira, que possui, por exemplo, 2,13 patentes por 10.000 habitantes.

Outras aglomerações espaciais do tipo AA aparecem no Paraná, com as microrregiões de Curitiba e Ponta Grossa e, isoladamente, no oeste, Cascavel. Destas, Curitiba destaca-se por causa da sua escala urbana e econômica e de sua base acadêmica e científica. Como descrevem Diniz e Gonçalves (2001), "nos anos 70, instalaram-se na região metropolitana de Curitiba algumas plantas industriais dos setores de metalurgia, mecânica, quimica e petroquimica, como Volvo, Bosch, Nippondenso, Siemens (Equitel), Furukawa e New Holland." Posteriormente, houve um processo de fortalecimento do complexo automotivo da região, que incorporou montadoras da Renault, Chrysler e Volkswagen/Audi, além da já estabelecida fábrica de caminhões Volvo.

Em Santa Catarina, destacam-se três aglomerações de microrregióes do tipo AA. Uma perto do litoral do Estado, composta por Joinville, Blumenau, Itajaí, São Bento do Sul e Rio do Sul, e outra mais a oeste do Estado, formada por Xanxerê, Concórdia e Joaçaba. Estas duas aglomerações só não estão unidas porque a microrregião de Curitibanos não possui patenteamento. A terceira é a de Florianópolis, Tubarão e Criciúma, também no litoral catarinense. De todas essas, a microrregião de Florianópolis desponta na área tecnológica por causa de escolas de engenharia, consideradas centros de excelência nas subáreas de mecânica e elétrica. Blumenau, Joinville e Itajaí são também importantes por causa de suas áreas industriais, que por estarem próximas a Florianópolis beneficiam-se de transbordamentos tecnológicos oriundos da capital catarinense.

No Rio Grande do Sul, duas aglomeraçóes espaciais sobressaem como AA. A primeira e principal é o corredor formado por Porto Alegre, Gramado-Canela, Montenegro, Caxias do Sul, Guaporé, Passo Fundo e Não-Me-Toque. A outra aglomeração é menos relevante e está localizada mais ao centro do Estado, sendo formada por Santa Cruz do Sul e Cachoeira do Sul. ${ }^{9}$ Conforme Diniz e Gonçalves (2001, p. 30), "a região de Porto Alegre-Caxias do Sul constitui a maior concentração populacional e industrial do Rio Grande do Sul, com população superior a quatro milhões de habitantes, incluindo uma rede de pequenas e médias cidades com estrutura industrial diversificada e integrada." Isto é coerente com o corredor tecnológico, visualizado na Figura 3, que se estende até Passo Fundo. É grande o potencial deste corredor para atividade tecnológica se considerarmos "a disponibilidade de infra-estrutura física e tecno-cientifica, a base econômica e industrial, a disponibilidade de serviços modernos e a qualificação do mercado de trabalho."

9 Santa Cruz do Sul possui 0,77 patentes por 10.000 habitantes e Cachoeira do Sul, 0,70. Ambas estão bem distante da aglomeração principal desse Estado, como Caxias do Sul, Passo Fundo e Porto Alegre, que possuem, respectivamente, $6,21,2,40$ e 2,16 patentes por 10.000 habitantes. 


\section{FIGURA 3 - MAPA DE SIGNIFICÂNCIA DE MORAN DAS REGIÓES SUDESTE E SUL}

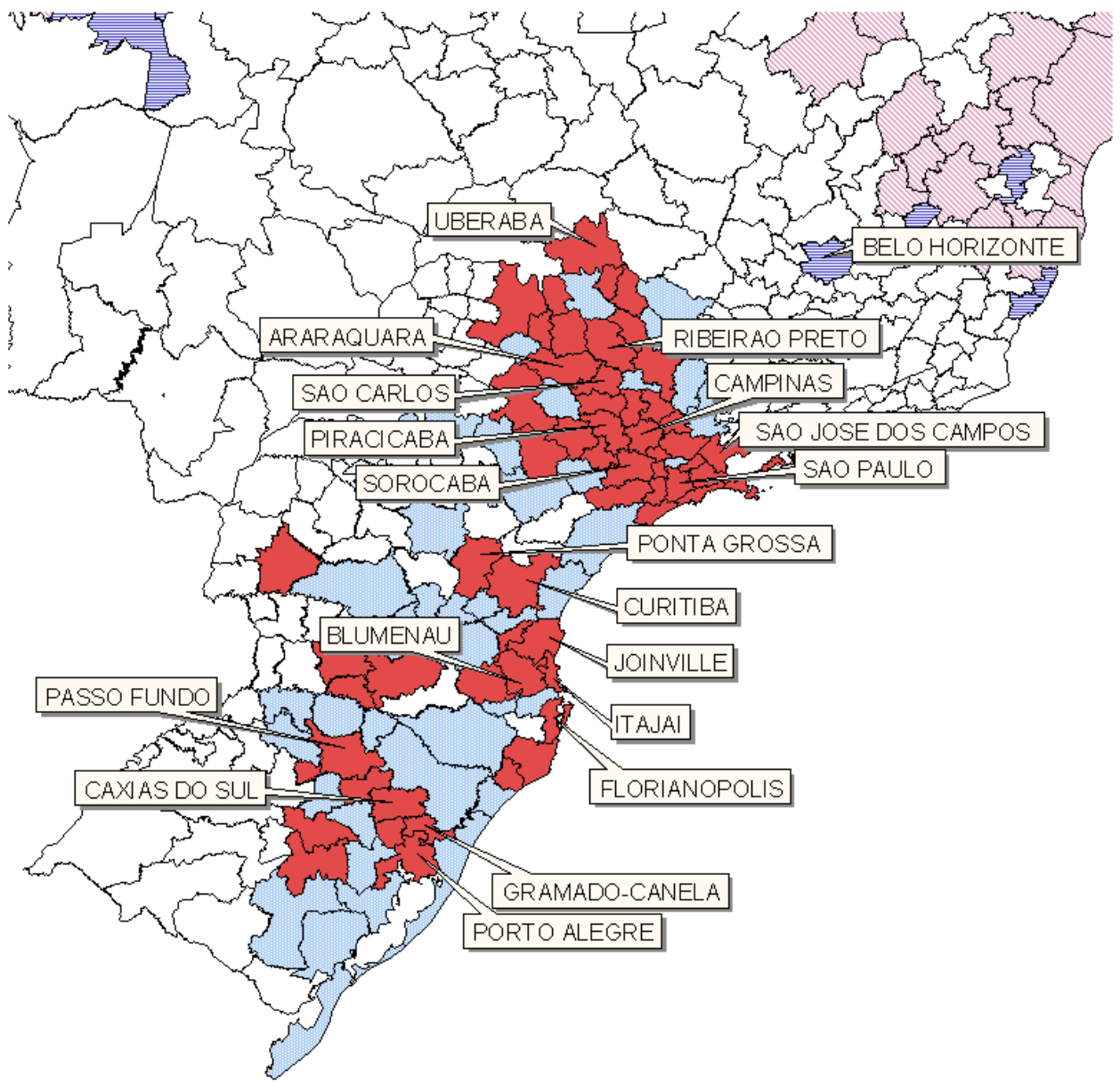

Moran Local - Patenteamento Per Capita

\begin{tabular}{|l}
\hline \\
Não significativo ou sem patentes \\
Alto-Alto \\
Baixo-Baixo \\
Alto-Baixo \\
Baixo-Alto
\end{tabular}

Nota: Figura 2 ampliada para as macrorregiões Sudeste e Sul.

Fonte: elaboração própria com base no programa $\operatorname{ArcGIS}^{\mathrm{TM}}$. 
Pode-se concluir que a atividade tecnológica brasileira, quando medida por patentes per capita, restringe-se a um polígono ainda mais restrito e descontínuo que a notória área poligonal das "aglomerações industriais relevantes" de Diniz e Crocco (1995), se considerarmos apenas as microrregiôes do tipo AA. Além destas áreas, existem algumas ilhas tecnológicas (regiões do tipo $\mathrm{AB}$ ), sendo a principal a microrregião de Belo Horizonte, cujo entorno limita a possibilidade de aproveitamento de transbordamentos tecnológicos.

Muitas das microrregiões citadas, que pertencem aos Estados de São Paulo, Paraná, Santa Catarina e Rio Grande do Sul, aparecem como observações extremas, tendo em vista seu excelente desempenho em termos de patenteamento. Estas são identificadas pela regra de dois desvios padrão (Tabela 5). Com exceção de Registro, que possui baixo índice de patenteamento per capita e está cercado por vizinhos com alto índice, todas as outras microrregióes destacam-se em termos de atividade inovadora e pertencem a regiôes dinâmicas do ponto de vista tecnológico (classificação AA).

TABELA 5 - MORAN LOCAL: MICRORREGIÓES DISCREPANTES

\begin{tabular}{llcc}
\hline Microrregião & UF & Moran Local & Associação Espacial \\
\hline Riberão Preto & SP & 1,1348 & AA \\
São Carlos & SP & 2,1349 & AA \\
Limeira & SP & 1,6420 & AA \\
Campinas & SP & 2,1861 & AA \\
Jundiaí & SP & 1,7421 & AA \\
Registro & SP & $-0,8793$ & BA \\
Osasco & SP & 1,2701 & AA \\
Itapecerica da Serra & SP & 1,5791 & AA \\
São Paulo & SP & 2,6864 & AA \\
Curitiba & PR & 1,3138 & AA \\
Joinville & SC & 1,8021 & AA \\
Rio do Sul & SC & 1,3304 & AA \\
Blumenau & SC & 1,4733 & AA \\
Florianópolis & SC & 1,4879 & AA \\
Criciúma & SC & 1,5442 & AA \\
Passo Fundo & RS & 1,0871 & AA \\
Caxias do Sul & RS & 1,9280 & AA \\
\hline
\end{tabular}

Nota: valores extremos identificados pela regra de dois desvios padrão.

Fonte: elaboração própria com base nas estatísticas do SpaceStat ${ }^{\mathrm{TM}}$. 


\subsection{Análise de Robustez dos Resultados}

Uma etapa importante da análise exploratória de dados espaciais é a verificação da estabilidade das estatísticas LISA diante da alternância do número de vizinhos da matriz de pesos. Isso é feito por meio das matrizes de transição de probabilidades, sugeridas originariamente por Le Gallo e Ertur (2003). São considerados robustos os resultados que permanecem inalterados à medida que se altera a matriz de pesos, modificandose o número de vizinhos daquela unidade espacial. Quanto mais próxima da unidade estiver a diagonal principal da matriz, mais robusto é considerado o resultado.

No nosso caso, as matrizes são construídas quando alteramos o número de vizinhos mais próximos de 10 para 15, 20, 25 e 30 microrregiões. A Tabela 6 mostra que a maioria das microrregiões permanece no mesmo tipo de agrupamento (NS, AA, BB, $\mathrm{AB}$ ou $\mathrm{BA}$ ), quando se altera o número de vizinhos mais próximos, no cálculo das estatísticas LISA, para a variável patentes per capita, usando nível de significância de Bonferroni de $5 \%$.

No primeiro exemplo, cerca de $84 \%$ dos casos não significativos com 10 vizinhos mais próximos continuam tendo a mesma classificação se mudamos o número de vizinhos para 15. A exceção são os dois casos considerados $A B$ com 10 vizinhos que passam a ser NS se a matriz de pesos muda para 15 vizinhos. Essas duas microrregiões são Pirapora e Barra de São Francisco, com 10 e 6 patentes cada. Portanto, este não é um problema sério porque estas duas microrregiões não estão entre as principais do País do ponto de vista tecnológico e apenas se destacaram, ainda que de forma instável, por causa da quase total ausência de atividade tecnológica dos seus vizinhos mais próximos.

Dois outros resultados interessantes são revelados pela Tabela 6. Primeiro, quanto mais vizinhos são adicionados, maior é o número de microrregiões com estatísticas LISA significativas, o que é mostrado na primeira linha de cada matriz. O número de localidades NS cai para 84\%, 75\%, 69\% e 67\% quando o número de vizinhos mais próximos se altera para 15, 20, 25 e 30, respectivamente. Segundo, destaca-se a estabilidade dos resultados AA e BB. A primeira classificação permanece inalterada em 98\% dos casos e, posteriormente, em 100\% das microrregiões. A segunda classificação continua a mesma em 96\% das microrregiões, em geral quando variamos o número de vizinhos até 30 . 
TABELA 6 - ANÁLISE DE ROBUSTEZ DAS ESTATÍSTICAS LISA PARA PATENTES PER CAPITA (em \%)

\begin{tabular}{|c|c|c|c|c|c|c|}
\hline & \multicolumn{6}{|c|}{$\mathrm{K}=10$ para $\mathrm{K}=15$} \\
\hline & $\mathrm{N}$ & NS & AA & $\mathrm{BB}$ & $A B$ & $\mathrm{BA}$ \\
\hline NS & 171 & 83,63 & 5,85 & 2,92 & 1,75 & 5,85 \\
\hline AA & 40 & 2,50 & 97,50 & 0,00 & 0,00 & 0,00 \\
\hline BB & 85 & 3,53 & 0,00 & 96,47 & 0,00 & 0,00 \\
\hline$A B$ & 2 & 100,00 & 0,00 & 0,00 & 0,00 & 0,00 \\
\hline BA & 23 & 13,04 & 0,00 & 0,00 & 0,00 & 86,96 \\
\hline \multicolumn{7}{|c|}{$\mathrm{K}=10$ para $\mathrm{K}=20$} \\
\hline & $\mathrm{N}$ & NS & AA & $\mathrm{BB}$ & $A B$ & $\mathrm{BA}$ \\
\hline NS & 171 & 74,85 & 8,19 & 5,85 & 2,92 & 8,19 \\
\hline AA & 40 & 0,00 & 100,00 & 0,00 & 0,00 & 0,00 \\
\hline BB & 85 & 3,53 & 0,00 & 96,47 & 0,00 & 0,00 \\
\hline$A B$ & 2 & 50,00 & 0,00 & 0,00 & 50,00 & 0,00 \\
\hline BA & 23 & 17,39 & 0,00 & 0,00 & 0,00 & 82,61 \\
\hline \multicolumn{7}{|c|}{$\mathrm{K}=10$ para $\mathrm{K}=25$} \\
\hline & $\mathrm{N}$ & NS & AA & $\mathrm{BB}$ & $A B$ & BA \\
\hline NS & 171 & 69,00 & 9,94 & 7,02 & 3,51 & 10,53 \\
\hline AA & 40 & 0,00 & 100,00 & 0,00 & 0,00 & 0,00 \\
\hline BB & 85 & 4,71 & 0,00 & 95,29 & 0,00 & 0,00 \\
\hline$A B$ & 2 & 50,00 & 0,00 & 0,00 & 50,00 & 0,00 \\
\hline BA & 23 & 17,39 & 0,00 & 0,00 & 0,00 & 82,61 \\
\hline \multicolumn{7}{|c|}{$\mathrm{K}=10$ para $\mathrm{K}=30$} \\
\hline & $\mathrm{N}$ & NS & AA & $\mathrm{BB}$ & $A B$ & BA \\
\hline NS & 171 & 66,67 & 10,53 & 6,43 & 4,09 & 12,28 \\
\hline AA & 40 & 0,00 & 100,00 & 0,00 & 0,00 & 0,00 \\
\hline BB & 85 & 2,35 & 0,00 & 97,65 & 0,00 & 0,00 \\
\hline$A B$ & 2 & 50,00 & 0,00 & 0,00 & 50,00 & 0,00 \\
\hline BA & 23 & 13,04 & 0,00 & 0,00 & 0,00 & 86,96 \\
\hline
\end{tabular}

Fonte: elaboração própria a partir das estatísticas LISA calculadas pelo SpaceStat ${ }^{\mathrm{TM}}$.

\section{CARACTERIZAÇÃO DA VIZINHANÇA DAS MICRORREGIÓES PATENTEA- DORAS}

Esta seção tem por finalidade caracterizar os vizinhos das microrregiôes patenteadoras em relação a algumas variáveis consideradas relevantes na literatura internacional sobre determinantes da atividade tecnológica e dos transbordamentos de conhecimento. A outra forma de ver a importância desta seção é que por meio dela podemos verificar 
quais os atributos da vizinhança são necessários para viabilizar a difusão da atividade tecnológica sob a escala inter-regional.

As variáveis testadas foram:

1- Índice de Herfindahl para medir a diversidade tecnológica das microrregióes, em relação aos 30 subdomínios tecnológicos, organizados pelo Observatoire des Sciences e des Techniques (OST, 2000) a partir das classes tecnológicas da Organização Mundial de Propriedade Intelectual (OMPI). ${ }^{10}$ Quanto mais próximo da unidade, menor é a diversidade tecnológica da microrregião. Ao contrário, quanto mais próximo de zero, mais subdomínios tecnológicos estão presentes na unidade territorial, o que significa que maior é a competência tecnológica local;

2- Índice de Herfindahl para medir a diversidade industrial das microrregiões, medida por dados de emprego da Relação Anual de Informações Sociais - RAIS - de 1998, desagregados em 22 setores industriais da Classificação Nacional de Atividades Econômicas a dois dígitos do IBGE (RAIS, 2000); ${ }^{11}$

3- Porcentual de concentração de pessoas ocupadas assalariadas nas quatro maiores empresas atuantes da unidade territorial (CR4), segundo o Cadastro Central de Empresas - 1998 (IBGE, 2002);

4- Grau de industrialização: participação porcentual da indústria no total do pessoal ocupado na microrregião. Os dados são referentes ao Cadastro Central de Empresas do IBGE de 1998 (IBGE, 2002);

5- Nível de escolaridade da população adulta: porcentual de pessoas com 25 anos ou mais que possui mais de 11 anos de estudo, segundo o IPEA (2004);

6- Quantidade de doutores em cursos de pós-graduação: docentes permanentes dos cursos de mestrado e doutorado das áreas de formação tecnológica, como Engenharias, Ciências Exatas e da Terra, Ciências Agrárias, Ciências Biológicas e da Saúde e Computação e Informática. Esta variável foi obtida por tabulação especial da CAPES e normalizada pela população de cada microrregião. Os dados são referentes a 1999;

10 Os subdomínios tecnológicos são: Componentes Elétricos, Audiovisual, Telecomunicações, Informática, Semicondutores, Ótica, Análise-Mensuração-Controle, Engenharia Médica, Química Fina Orgânica, Química Macromolecular, Farmacêuticos-Cosméticos, Biotecnologia, Materiais-Metalurgia, Produtos Agrícolas e Alimentares, Química de Base, Engenharia Química, Tratamento de Superfícies, Têxtil e Papel, Procedimentos Térmicos, Meio Ambiente, Máquinas e Ferramentas, Motores-Bombas-Turbinas, Componentes Mecânicos, Manutenção-Gráfica, Aparelhos Agrícolas e Alimentares, Transportes, Técnicas Nucleares, Espacial-Armamentos, Consumo das Famílias e Construção Civil.

11 Existem 23 divisões industriais, de acordo com a CNAE. Entretanto, optou-se por não incluir no cálculo a divisão reciclagem. 
7- Quantidade de empregados com formação em Física, em Química, em Engenharias, em Análise de Sistemas e Programação, divididos pelo total de empregados em 1998, segundo a RAIS (RAIS, 2000).

É usado o diagrama bivariado de Moran, no qual há a variável patenteamento per capita no eixo das abscissas e uma das variáveis acima, defasada espacialmente, no eixo das ordenadas. A Tabela 7 traz o grau de associação entre as duas variáveis, equivalente ao coeficiente de ajuste de um modelo de regressão, para várias estruturas de vizinhança.

\section{TABELA 7 - INDICADOR GLOBAL BIVARIADO DE AUTOCORRELAÇÃO ESPACIAL}

\begin{tabular}{lccccc}
\hline Variáveis & \multicolumn{5}{c}{ Vizinhos mais próximos } \\
\cline { 2 - 6 } & 10 & 15 & 20 & 25 & 30 \\
\hline PATPOP x W_HERF-TECNOLOGIA & $-0,20$ & $-0,19$ & $-0,18$ & $-0,17$ & $-0,15$ \\
PATPOP x W_HERF-INDÚSTRIA & $-0,19$ & $-0,19$ & $-0,19$ & $-0,18$ & $-0,17$ \\
PATPOP x W_CR4 & $-0,30$ & $-0,28$ & $-0,26$ & $-0,25$ & $-0,24$ \\
PATPOP x W_PERPOIND & 0,24 & 0,22 & 0,21 & 0,21 & 0,20 \\
PATPOP x W_SUPERIOR & 0,26 & 0,25 & 0,24 & 0,24 & 0,23 \\
PATPOP x W_PHDPOP & 0,09 & 0,08 & 0,06 & 0,07 & 0,08 \\
PATPOP x W_EMPTEC & 0,16 & 0,15 & 0,14 & 0,12 & 0,11 \\
\hline
\end{tabular}

Notas: PATPOP $=$ Patenteamento per capita;

W_HERF-TECNOLOGIA = Defasagem espacial do indicador de Herfindahl da tecnologia;

W_HERF-INDÚSTRIA = Defasagem espacial do indicador de Herfindahl da indústria;

W_CR4 = Defasagem espacial da razão de concentração do pessoal ocupado;

W_PERPOIND = Defasagem espacial do grau de industrialização;

W_SUPERIOR = Defasagem espacial do grau de escolaridade da população adulta;

W_PHDPOP $=$ Defasagem espacial do número de doutores per capita;

W_EMPTEC $=$ Defasagem espacial do número de empregados com formação tecnológica .

Todos as estatísticas são significativas a $0,01 \%$, computadas com 10.000 permutações.

Fonte: elaboração própria com base no programa GEODa 0.9.5-i (Beta).

Verifica-se que há associação negativa entre o patenteamento per capita de uma microrregião e a razão de concentração das quatro maiores empresas das unidades espaciais vizinhas, seja qual for o número de vizinhos. Entretanto, a intensidade da relação negativa diminui à medida que adicionamos mais vizinhos na matriz de vizinhança. A relação negativa entre as duas variáveis mostra que microrregiões com maior atividade tecnológica estão inseridas em espaços caracterizados por baixa concentração econô- 
mica. Acreditamos que esse resultado reflita o fato de que microrregiões de baixa atividade tecnológica são também, em sua maioria, aquelas que abrigam poucas e/ou grandes unidades econômicas, as quais funcionam como âncoras da economia local, pouco diversificada. Nos casos principais, como Campinas ou Joinville, mesmo que haja grandes empresas na economia, o número de empregos totais encontra-se mais eqüitativamente distribuído entre o número elevado de estabelecimentos.

De forma semelhante, há relação negativa entre patenteamento per capita e ausência de diversidade tecnológica dos vizinhos. Isto sugere que a competência regional em várias áreas tecnológicas pode sustentar maior atividade e dinamismo tecnológico. Entretanto, diversidade tecnológica não implica necessariamente diversidade industrial porque a firma de um setor pode patentear em diversos setores, inclusive diferentes do seu próprio. Por isso, é necessário calcular o mesmo indicador para a indústria, tomando como medida o emprego regional industrial. A Tabela 7 também mostra associação negativa entre atividade tecnológica e especialização industrial. Esses resultados sugerem que o caso brasileiro está de acordo com a tese de Jacobs (1969) sobre a importância da diversidade para promover inovações.

Todas as outras quatro variáveis apresentam correlação espacial positiva, embora varie sua intensidade. As relações mais fortes estão vinculadas com o nível de escolaridade dos indivíduos adultos (SUPERIOR) e com o grau de industrialização (PERPOIND). Microrregiões de elevado desempenho tecnológico são vizinhas de microrregiões industrializadas que dispõem de população qualificada. Esse resultado é coerente com aqueles encontrados por Audretsch e Feldman (1996) ou Carlino et al. (2001).

Também há relação positiva, embora menos forte que as anteriores, entre patenteamento e presença de doutores (PHDPOP) e de empregados com formação em áreas tecnológicas (EMPTEC). Se a primeira puder ser tomada como proxy da capacidade de realização de P\&D universitário e a segunda como proxy da atividade de P\&D industrial, isso pode ser visto como indícios de que a atividade tecnológica necessita estar inserida em regiões que tenham tanto a pesquisa universitária quanto o esforço empresarial voltado para P\&D. Audretsch e Feldman (1996) mostraram que trabalho qualificado e pesquisa universitária influenciavam positivamente a concentração espacial da inovação. Carlino et al. (2001) encontraram evidências de que a existência de alto grau de escolaridade da população adulta é um fator que estimula o patenteamento per capita, confirmando a importância do papel educacional na criação tecnológica.

Com base nessas evidências, podemos concluir que baixos índices de industrialização, de escolaridade da população adulta, de doutores, de empregados com formação tecnológica, de diversidade tecnológica e altos níveis de concentração empresarial funcionam como barreiras ao processo de difusão espacial da atividade tecnológica entre 
as microrregiões brasileiras, medida por patentes. Essas barreiras espaciais impedem que transbordamentos de conhecimento operem, difundindo inovações entre microrregiốes vizinhas. No caso brasileiro, essas barreiras parecem inexistir no interior da grande aglomeração espacial tecnológica do Estado de São Paulo e das aglomerações Porto Alegre-Caxias do Sul-Passo Fundo e Blumenau-Joinville-Itajaí-Florianópolis e de Curitiba e adjacências.

\section{CONCLUSÕES}

Por meio da aplicação da análise exploratória de dados espaciais foi possível alcançar três principais conclusões.

Primeiro, é possível rejeitar a hipótese de aleatoriedade na distribuição do patenteamento per capita brasileiro, ou seja, constatou-se que a atividade tecnológica é caracterizada por autocorrelação espacial global. Isto equivale a dizer que microrregiões com elevado índice de patentes per capita são vizinhas de outras microrregióes com valores semelhantes para esta variável.

Segundo, nota-se que prevalece o regime de polarização Norte-Sul na distribuição da atividade tecnológica brasileira. Este resultado corrobora conclusões de trabalhos anteriores e torna adequada a caracterização das macrorregiões Norte, Nordeste e Centro-Oeste como "Região Vazia e Estagnada" em relação ao seu potencial para gerar atividade produtiva intensiva em conhecimento. Elas são marcadas pela sua homogeneidade em termos de baixa atividade tecnológica. Ao contrário, as macrorregiões Sudeste e Sul apresentam maior riqueza de padrões espaciais de inovação, destacando-se as aglomerações espaciais significativas do Estado de São Paulo, de Porto Alegre-Caxias do Sul-Passo Fundo, de Blumenau-Joinville-Itajaí-Florianópolis e de Curitiba. Estas microrregiões formam um polígono ainda mais restrito e descontínuo que o das "aglomerações industriais relevantes".

Terceiro, é possível afirmar que a qualidade da vizinhança é fator essencial para o processo de transbordamento tecnológico. Podemos concluir que baixos índices de industrialização, de escolaridade da população adulta, de doutores, de empregados com formação tecnológica, de diversidade tecnológica e altos níveis de concentração empresarial funcionam como barreiras ao processo de difusão espacial da atividade tecnológica entre as microrregiões brasileiras, medida por patentes. Todos esses fatores revelaram-se importantes qualificadores da vizinhança das microrregiões patenteadoras. 
Estes padrões espaciais, revelados pela técnica utilizada neste trabalho, propiciam base empírica sobre a qual futuras especificações econométricas podem tornar mais explícitos a existência e o alcance do processo de difusão espacial do conhecimento. Estes modelos também serão importantes para determinar as causas da mudança técnica em termos microrregionais, levando-se em conta o fato de o espaço ter sido considerado importante na dinâmica da atividade tecnológica brasileira.

\section{REFEREANCLAS BIBLIOGRÁFICAS}

Acs, Z. J., Audretsch, D. B. Patents as a measure of innovative activity. Kyklos, v. 42, n. 2, p. 171-180, 1989.

Albuquerque, E. M.; Simões, R.; Baessa, A.; Campolina, B.; Silva, L. A distribuição espacial da produção científica e tecnológica brasileira: uma descrição de estatísticas de produção local de patentes e artigos científicos. Revista Brasileira de Inovação, Rio de Janeiro, v. 1, n. 2, p. 225-251, 2002.

Anselin, L. SpaceStat version 1.80: user's guide. Urbana-Champaign: University of Illinois, 1995a.

. Local indicators of spatial association-LISA. Geographical Analysis, v. 27, p. 93-115, 1995b.

. SpaceStat tutorial: a workbook for using SpaceStat in the analysis of spatial data. Urbana-Champaign: University of Illinois, 1992.

. Spatial econometrics: methods and models. Boston: Kluwer Academic, 1988. 284p.

. The Moran scatterplot as an ESDA tool to assess local instability in spatial associaton. In: Fischer, M.; Scholten, H. J.; Unwin, D. (Eds.), Spatial analytical perspectives on GIS. Londres: Taylor \& Francis, 1996.

Anselin, L.; Bera, A. Spatial dependence in linear regression models with an introduction to spatial econometrics. In: Ullah, A.; Giles, D. E. A. (Eds.), Handbook of applied economic statistics. Nova York: Marcel Dekker, 1998, p. 237-289.

Audretsch, D. B.; Feldman, M. P. R\&D spillovers and the geography of innovation and production. American Economic Review, v. 86, n. 3, p. 630-640, 1996.

Breschi, S. Agglomeration economies, knowledge spillovers, technological diversity and spatial clustering of innovations. Liuc Papers, n. 57, Serie Economia e Impresa 15, outubro, 1998.

Carlino, G.; Chatterjee, S.; Hunt, R. Knowledge spillovers and the new economy of cities. Philadelphia: Federal Reserve Bank of Philadelphia, set., 2001. (Working Paper; 01-14).

Christäller, W. Central places in southern Germany. Prentice-Hall, Englewood Cliffs, NJ, 1966. 
Diniz, C. C. A nova configuração urbano-industrial no Brasil. In: Encontro Nacional de Economia, 27, Belém. Anais... Belém: ANPEC, 1999.

. Desenvolvimento poligonal no Brasil: nem desconcentração nem contínua polarização. Nova Economia, Belo Horizonte, v. 3, n. 1, 1993.

Diniz, C. C.; Crocco, M. A. Reestruturação econômica e impacto regional: o novo mapa da indústria brasileira. Nova Economia, Belo Horizonte, v. 6, n. 1, jul. 1996.

Diniz, C. C.; Gonçalves, E. Knowledge economy and regional development in Brazil. In: Les Troisièmes Journées de la Proximité - The Third Congress on Proximity, Paris, França, 13-14 dez., 2001.

Diniz, C. C.; Razavi, M. São José dos Campos and Campinas: state-anchored dynamos. In: Markusen, Ann; Lee, Yiong-Sook; Digiovanna, S. (Eds.), Second tier cities: rapid growth beyond the metropolis. London: University of Minnesota Press, 1999. p. 97-126

Fischer, M. M.; Varga, A. Spatial knowledge spillovers and university research: evidence from Austria. Annals of Regional Science, v. 37, 2003, p. 303-322.

Griliches, Z. Patent statistics as economic indicators: a survey. Journal of Economic Literature, v. 28, n. 4, p. 1661-1707, dez. 1990.

IBGE. Base de informações municipais. Rio de Janeiro: IBGE, 2002, 3 ed. [CD$\mathrm{ROM}]$

IPEA. Dados sobre educação - 2000 . 2004. Disponível em: < http://www.ipeadata.gov. br>. Acesso em: 10 dez. 2004.

Jacobs, J. The economy of cities. Nova York: Random House, 1969.

Jaffe, A. B. Real effects of academic research. American Economic Review, v. 79, n. 5, p. 957-970, dez. 1989.

Jaffe, A.; Trajtenberg, M.; Henderson, R. Geographic localization of knowledge spillovers as evidenced by patent citations. Quarterly Journal of Economics, v. 108, n. 3, ago. 1993.

Le Gallo, J.; Ertur, C. Exploratory spatial data analysis of the distribution of regional per capita GDP in Europe, 1980-1995. Papers in Regional Science, v. 82, p. 175$201,2003$.

Messner, S. F; Anselin, L.; Baller, R. D.; Hawkins, D. F; Deane, G.; Tolnay, S. E. The spatial patterning of county homicide rates: an application of exploratory spatial data analysis. Journal of Quantitative Criminology, v. 15, n. 4, p. 423-450, 1999.

Moreno-Serrano, R.; Paci, R.; Usai, S. Spatial spillovers and innovation activity in European regions. Centro Riserche Economiche Nord Sud, set., 2004. (Working paper ; 03-10).

Observatoire des Sciences et des Techniques. Science \& Technologie: indicateurs 2000. Paris: Economica, 2000. 
RAIS. Relação anual de informações sociais - 1998. Brasília: Ministério do Trabalho, 2000 [CD-ROM].

Scherer, F. M. The propensity to patent. International Journal of Industrial Organization, v. 1, p. 107-128, 1983.

Silva, Leandro; Simões, Rodrigo. Oportunidades tecnológicas e produção científica: uma análise microrregional para o Brasil. EURE, Santiago, v. 30, n. 90, p. 85$102,2004$.

Sun, Y. Spatial distribution of patents in China. Regional Studies, v. 34, n. 5, p. 441$454,2000$.

Varga, A. University research and regional innovation: a spatial econometric analysis of academic technology transfers. Boston/Dordrecht/London: Kluwer Academic Publishers, 1998. 